Open Access

\title{
International training programs on eating disorders for professionals, caregivers, and the general public: A scoping review
}

Myra Piat ${ }^{1 *}$, Alexis Pearson ${ }^{2}$, Judith Sabetti ${ }^{2}$, Howard Steiger $^{1}$, Mimi Israel ${ }^{1}$ and Shalini Lal ${ }^{3}$

\begin{abstract}
This review identified and synthesized published training programs on eating disorders (ED) (anorexia nervosa or bulimia nervosa) for professionals, natural supporters of people with ED, or the public. A scoping review using the Arksey and O'Malley (2005) framework was conducted. Four data bases were searched, for all years, and manual searches from three additional sources were also conducted. Experts on ED were consulted for validation of the identified studies. A narrative synthesis was performed. A total of 20 evaluation studies from five countries were identified, and reviewed in relation to 14 ED training programs. Characteristics of the training programs, and study characteristics, were highly diverse, as shown on Table 1 which compiles results from the charted data. Evaluations were equally divided between training for healthcare and education professionals (9), and training for families or other carers of people with ED (10). One study evaluated ED training for the general public. We found that training orientation varies with the interests and needs of different trainee groups. While most studies assessed trainee outcomes, future research needs to give greater consideration to patient perspectives, and to the relationship between training and evaluation approaches, improved knowledge, and better care.
\end{abstract}

Keywords: Training, Eating disorders, Anorexia nervosa, Bulimia nervosa, Scoping review, Healthcare professionals, Educators, Families

\section{Background}

This scoping review was conducted to support the development of an evidence-informed training program for primary healthcare providers through the Douglas Eating Disorders Program in Montreal, Canada. The research question was broad: What training programs on eating disorders (ED) are available for professionals, or natural supporters of people with ED? The review aimed to identify, and describe, published training programs that have been both implemented and evaluated. We were interested in identifying training focused on assessment, treatment and support for people with ED, as well as prevention-focused training.

\section{Method}

The scoping review methodology is ideal for rapidly mapping a field of research with a view toward

\footnotetext{
* Correspondence: myra.piat@douglas.mcgill.ca

'Douglas Mental Health University Institute, McGill University, 6875 LaSalle Boulevard, Verdun, Montreal, Québec H4H 1R3, Canada

Full list of author information is available at the end of the article
}

identifying gaps in research or practice. Scoping is usually exploratory, according to Davis et al. [1] The present review used the 6-staged framework for scoping reviews developed by Arksey and O'Malley [2], which is structured in line with a systematic review: development of the research question, study selection, charting, summarizing and reporting results. We also included a consultation stage with experts in the ED field.

\section{Search procedure}

A systematic literature search was conducted using electronic databases, and manual search techniques. Four databases were included: Ovid Medline, Pubmed, Embase, and a keyword search of the Scopus database, using the terms "eating disorders", "training", and "primary healthcare". Date restrictions were not applied, as we were interested in identifying all published training programs on ED. Manual 
Table 1 Characteristics of studies in the review

\begin{tabular}{|c|c|c|}
\hline $\begin{array}{l}\text { The student body: } \\
\text { promoting health } \\
\text { at any size }\end{array}$ & $\begin{array}{l}\text { McVey, } 2007 \text { [17] } \\
\text { (Canada) }\end{array}$ & $\begin{array}{l}\text { A prevention program for elementary } \\
\text { school teachers and public health } \\
\text { practitioners. The web-based approach } \\
\text { made the program accessible both inside } \\
\text { and outside school hours }\end{array}$ \\
\hline $\begin{array}{l}\text { The Meal Support } \\
\text { Training (MST) }\end{array}$ & $\begin{array}{l}\text { Cairns, } 2007 \text { [28] } \\
\text { (Canada) }\end{array}$ & $\begin{array}{l}\text { Introduces concept of meal support; helps } \\
\text { others understand feelings of youth with } \\
\text { disordered eating around meals; provides } \\
\text { approaches/strategies for meal support }\end{array}$ \\
\hline \multirow[t]{2}{*}{$\begin{array}{l}\text { Maudsley eating } \\
\text { disorder collaborative } \\
\text { care workshops }\end{array}$} & $\begin{array}{l}\text { Sepulveda, } 2008 \\
{[26] \text { (UK) }}\end{array}$ & $\begin{array}{l}\text { Aims to strengthen knowledge and skills of } \\
\text { carers, while reducing the burden of caring } \\
\text { for their children with ED. Elements of } \\
\text { approach: Skill-based instruction; group } \\
\text { format; observation of others' skills; } \\
\text { weekly goals }\end{array}$ \\
\hline & $\begin{array}{l}\text { Sepulveda, 2008a } \\
\text { [23] (UK) }\end{array}$ & $\begin{array}{l}\text { Aims to strengthen knowledge and skills of } \\
\text { carers, and reduce the emotional burden of } \\
\text { caring for their children with ED. Approach } \\
\text { includes theory and instruction; } \\
\text { demonstration and practice; telephone- } \\
\text { administered skills coaching based on } \\
\text { behavior therapy }\end{array}$ \\
\hline $\begin{array}{l}\text { Maudsley eating } \\
\text { disorder collaborative } \\
\text { care workshops (continued) }\end{array}$ & $\begin{array}{l}\text { Macdonald, } 2011 \\
\text { (UK) }\end{array}$ & $\begin{array}{l}\text { Aimed at improving communication and } \\
\text { reducing social impact of ED for families by } \\
\text { addressing negative QOL, burden of illness, } \\
\text { distress and expressed emotion. Evidence- } \\
\text { based approach, psycho-education } \\
\text { principles and motivational interviewing }\end{array}$ \\
\hline $\begin{array}{l}\text { Overcoming Anorexia } \\
\text { Online (OAO) }\end{array}$ & $\begin{array}{l}\text { Grover, } 2011 \text { [20] } \\
\text { (UK) }\end{array}$ & $\begin{array}{l}\text { Aims to provide information, promote self- } \\
\text { monitoring and teach skills to identify, } \\
\text { understand, and manage Anorexia. } \\
\text { Interactive, web-based approach; uses CBT } \\
\text { (Williams, 2002, 2009) and systemic } \\
\text { framework (Dummett, 2006) }\end{array}$ \\
\hline $\begin{array}{l}\text { The care and } \\
\text { understanding of } \\
\text { people with eating } \\
\text { disorders (ENB N46) }\end{array}$ & $\begin{array}{l}\text { Abuel-Ealeh, } \\
2001 \text { [12] (UK) }\end{array}$ & $\begin{array}{l}\text { Aim of program to raise professionals' } \\
\text { knowledge and awareness of EDs; increase } \\
\text { confidence and skills for working with ED } \\
\text { clients. A university-level course }\end{array}$ \\
\hline
\end{tabular}

Trainees

Target population Evaluation method Evaluation findings

Ontario community McVey, $2005[18]$ Increase community-based practitioners' knowledge, involvement and level of comfort to treat clients with EDs; to foster linkages among practitioners in and across regions of the province. Based on an school boards \& public children Quantitative; prehealth departments

survey

$\uparrow$ knowledge re ED, body eating disorders

Elementary teachers; public health

Elementary school RCT

professionals children

Parents, caregivers,

friends of eating-

Children with ED Mixed methodology

Family members of

Children treated

for ED at South

Quantitative pre-

people with all forms

of $E D$

London \&

Hospital

post design +3

issues; $\uparrow$ confidence to treat or teach on ED; better practitioner links

teacher knowledge re dieting $\&$ peer influence; high satisfaction w/ online tools \& self as role model

Family members of ED People with ED

Quantitative and patients qualitative

+ parent ratings on manual \& video, especially re patient input. Tools support parental instincts

$\downarrow$ carer distress and care burden over time; benefits = new skills, exchanging with others $\begin{array}{ll}\begin{array}{l}\text { Family and carers of } \\ \text { people with ED }\end{array} & \begin{array}{l}\text { People with } \\ \text { anorexia }\end{array}\end{array} \quad$ Qualitative

Carers (relatives,

People with AN, all ages and stages of someone with broadly illness defined anorexia

Mainly nursing students People with ED (1 OT; service users) (future clients of trainees)

Quantitative descriptive (some open questions)
Quant results not sig Qualitative: $\uparrow$ understanding of how reactions \& interactions $\mathrm{w} /$ patients impact outcomes.

Skills transfer \&supplementary coaching were highly valued; positive change for coaching group \& acceptability of intervention

Main $\mathrm{H}: \downarrow$ carer distress after OAO supported (vs. controls). Module on communication was most useful.

$81.5 \%$ program completer later worked in ED fields: $77.7 \%$ interested in further training 
Table 1 Characteristics of studies in the review (Continued)

Collaborative care skills Pepin \& King, 2013 Replication of the Maudsley eating disorder training workshops

collaborative care workshops in Australia

Goodier, 2014 [19] Adaptation of the new Maudsley method (Australia) for parent skills training with children and adolescents

Mental health first aid training course for

Hart, 2012 [27] Aims to improve mental health literacy in (Australia) the social networks of individuals with ED; translates the MHFA protocol, which is an action plan that provides information on various mental illnesses to the public, into a program specifically for EDs

(No title)

Chally, 1998 [16] A prevention program for school personnel aimed at providing training to recognize students at risk for ED, or to identify signs and symptoms in students with whom they interact daily

The eating disorder curriculum for primary care providers

Gurni \& Halmi, 2001 [13] (USA)

Aims at providing a first step in training social workers to serve as eating disorder therapists in primary care clinics

Group Parent Training program (GPT)

Zucker, 2005 [26] (USA)

Assists caregivers in managing the child's ED, and facilitates a healthy home environment for sustained change. Draws on narrative family therapy and psycho-educational approaches, emotion-focused therapy,

mindfulness strategies, dialectical behavio therapy

Zucker, 2006 [24] Overall aim to maximize the effectiveness of (USA) parent involvement while minimizing burden in managing EDs; the main approach used dialectical behavior therapy (DBT) adapted to a group parent format. Course content also based on social cognitive, and learning theories

Eating disorders and mental health—-the EAT framework
Aims to increase the capacity of oral health professionals to deliver ED-specific secondary prevention to patients suspected of disordered eating; uses a framework based on transtheoretical model and brief motivational interviewing

DeBate, 2012 [10] To increase knowledge, skill \& self-efficacy (USA) among dental and dental hygiene students for dealing with oral manifestations of disordered eating; approach is a theory-based framework based on brief motivational interviewing (B-MI)
People with ED

living with family

members

Quantitative pre-

follow-up

Parents of children

or adolescents in

treatment for $\mathrm{ED}$

General public

Children or

qualitative

adolescents with ED

Personal contacts

family, friends,

Quantitative; pre-

post repeated

who may need help

for ED

High school educators and staff

\section{High school} students potentially post test, contro at risk for ED group design

9 female social workers

minority group

members, low-

income, at risk

for ED

Parents/carers of

patients in the

Duke ED Program

Patients in the Duke ED Program

Quantitativ (pilot study)

Qualitative (focus groups)

(No answer)

Adolescent

outpatients from

Quantitative

the university

affiliated medical

center

Oral health providers

Dental patients

Quantitative pre suspected of having post design an ED

\section{Dental and dental} hygiene students

Dental patients with Quantitative, group
signs of disordered randomized control eating design $\uparrow$ adaptive coping strategies over time; $\downarrow$ over-

nvolvement (not EE).

Training helped re: managing illness \& family dynamics: broke isolation; peer support

$\uparrow$ ED knowledge \& first aid strate-gies; $\downarrow$ stigma (social distance): $\uparrow$ confidence to identify \& help someone with ED.

knowledge \& ability to identify students at risk; $\uparrow$ belief in getting help; $\downarrow$ belief that thin $=$ success.

$\uparrow$ ED knowledge re

assessment \& treatment; better diagnostic skills post training.

Parent desire for psychoeducation materials $\mathrm{W} / \mathrm{skills}$ based approach; ideas re $\uparrow$ peer support.

management of ED, but lso better parents; ED skills transfer to other areas; $\uparrow$ stress management

$\uparrow$ self-efficacy; $\uparrow$ knowledge re oral manifestations of $E D$, reatments, attitudes 2nd-ary prevention 
Table 1 Characteristics of studies in the review (Continued)

\begin{tabular}{|c|c|c|c|c|c|c|}
\hline $\begin{array}{l}\text { The parent partner } \\
\text { program }^{\text {TM }}\end{array}$ & $\begin{array}{l}\text { Haltom, } 2012 \text { [21] } \\
\text { (USA) }\end{array}$ & $\begin{array}{l}\text { To provide carers with knowledge and skills } \\
\text { to support people with ED, but also bring } \\
\text { together a community of professionals, carers } \\
\text { and advocates around integrated treatment; } \\
\text { uses philosophy of mutual support and } \\
\text { learning based on research by Bronfenbrenner } \\
\text { (Cochran \& Henderson, 1986) }\end{array}$ & $\begin{array}{l}\text { Family, friends caring } \\
\text { for ED patients }\end{array}$ & Anyone with ED & $\begin{array}{l}\text { Quantitative pre- } \\
\text { post test design }\end{array}$ & $\begin{array}{l}\uparrow \text { knowledge re ED, } \\
\text { treatment; how to provide } \\
\text { support, } \uparrow \text { support re carers \& } \\
\text { empathy re people W/ ED. }\end{array}$ \\
\hline \multirow[t]{2}{*}{ Body and self esteem } & $\begin{array}{l}\text { Rosenvinge, } 2003 \\
\text { [15] (Norway) }\end{array}$ & $\begin{array}{l}\text { Increase clinical competence of health providers } \\
\text { in ED; encourage interdisciplinary work at } \\
\text { local level, and therapists to as ED resources } \\
\text { in health care services; approaches: family } \\
\text { therapy; CBT); psychodynamic therapy }\end{array}$ & $\begin{array}{l}\text { Local multi-disciplinary } \\
\text { health care professionals }\end{array}$ & $\begin{array}{l}\text { Prospective clients } \\
\text { of trainees }\end{array}$ & $\begin{array}{l}\text { Quantitative pre- } \\
\text { post design + } \\
1 \text { year follow-up }\end{array}$ & $\begin{array}{l}\text { Needed more time to learn } \\
\text { clinical skills, management, } \\
\text { therapy; } \uparrow \text { confidence to treat } \\
\text { @ follow-up. }\end{array}$ \\
\hline & $\begin{array}{l}\text { Pettersen, } 2012 \\
{[14] \text { (Norway) }}\end{array}$ & $\begin{array}{l}\text { Addresses professionals' needs for clinical } \\
\text { competence and better understanding of } \\
\text { the benefits of inter-professional collaboration } \\
\text { in treating ED; approach is "exchange based" }\end{array}$ & $\begin{array}{l}\text { Doctors, nurses, } \\
\text { psychologists \& other } \\
\text { health care workers }\end{array}$ & (No answer) & Qualitative & $\begin{array}{l}\text { Desire for } \uparrow \text { ED services \& } \\
\text { training after program \& to } \\
\text { work inter-professionally }\end{array}$ \\
\hline
\end{tabular}


searches for additional studies included: 1) the reference lists of all selected articles; 2) tables of contents for 2009-2014 in the following journals: The International Journal of Eating Disorders; Eating Disorders: The Journal of Prevention and Treatment; European Eating Disorders Review; Eating Disorders; and the Journal of Eating Disorders; and 3) websites for the Academy for Eating Disorders; National Eating Disorder Association (US), and National Eating Disorder Information Canada. Experts on ED were consulted (HS, MI) in order to validate the study selection, and suggest names of other key authors.

\section{Selection criteria}

Inclusion criteria for the study were: 1 ) published articles in English or French; 2) all study designs; 3) a trainee group: professionals from any discipline; family members or other caregivers of people with ED; the general public; and 4) a target group: people of any age diagnosed, or at risk for, anorexia nervosa or bulimia nervosa. The exclusion criteria were: 1) non-research studies and books, except for descriptions of ED training programs where an evaluation was published separately; and 2) ED intervention studies.
The initial electronic search identified 675 articles, with 473 remaining after 202 duplicates were removed. Titles and abstracts of the 473 articles were independently screened for relevance by two researchers (MP and AP) based on the inclusion and exclusion criteria, and 50 articles selected. The same team members then read the selected articles in their entirety. Thirty-four articles (34/50) were excluded for two reasons: 1) the program described was not a training program; or 2) no evaluation of the training was published. This resulted in a total of 14 articles for the review. Disagreements related to the inclusion of papers were discussed and resolved by involving a third team member (JS). The manual search of reference lists for the 14 selected articles resulted in an additional 6 articles, for a total of 20. No further articles emerged from the secondary searches of ED journals, or the organization websites. It should be noted that additional publications exist describing programs for 5 of the 20 selected articles. While not part of the review, these articles may be consulted for supplemental information [3-7]. Fig. 1 presents a flow diagram for the study selection process.

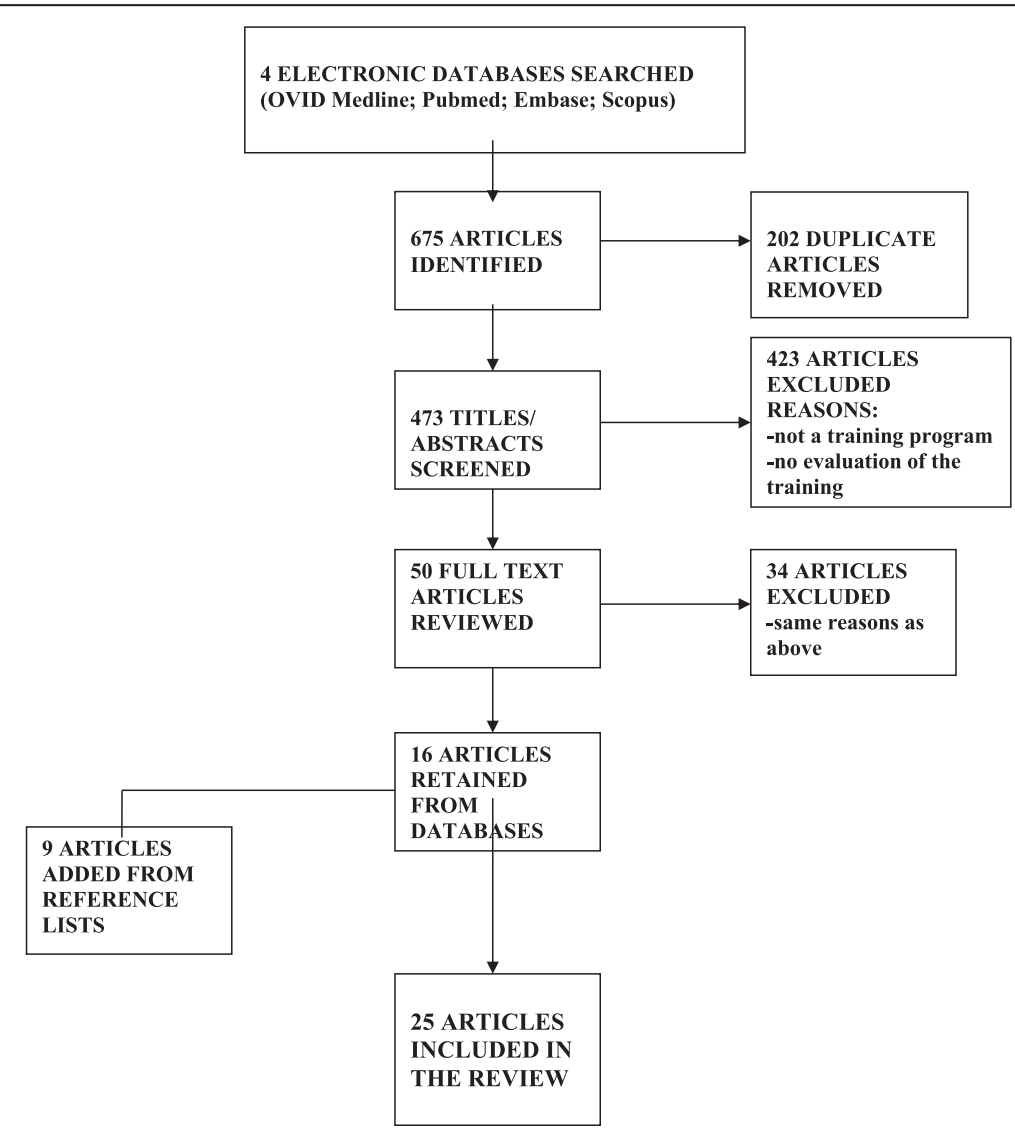

Fig. 1 Flow diagram of study selection process 


\section{Data extraction and synthesis}

The research team developed a data charting form consisting of three overall categories: reference information on the studies (title, authors, journal, publication year, author disciplines, country); training program details (program name, objective, approach, setting, training description, trainee and target populations); and details of the evaluations: (purpose, methodology, participants, data collection, study results/outcomes, study limitations/contributions, recommendations). The data were charted by two researchers (AP, JS), in conjunction with the project lead (MP). A narrative synthesis of the data was performed. The narrative synthesis is a conceptual and interpretive approach focused on the relevance and contribution of evidence rather than rigidly determined methodological criteria; it is especially appropriate for synthesizing methodologically dissimilar studies $[1,8]$.

\section{Results}

\section{Study characteristics}

The 20 evaluation studies reviewed concern a total of 14 ED training programs. The studies represent five countries: Canada (3), UK (5), USA (7), Australia (3), and Norway (2). Table 1 presents the 20 studies in terms of training program identification; training objective/approach; identification of trainee and target populations; evaluation method and findings. The studies included four trainee groups: healthcare professionals (clinicians, students, administrators, and multidisciplinary teams, $n=8$ ); educators (teachers, administrators, school staff, $n=3$ ); natural supporters (parents or other family members, carers, friends, $n=10)$; and the general public $(n=1)$. Target populations were children and/or adolescents $(n=8)$ or people of all ages $(n=14)^{1}$. For 17 studies the target population had a diagnosed or suspected ED, while the remaining three concerned populations at-risk.

The evaluation studies employed a heterogeneous mix of study designs: there were 14 quantitative studies (8 pre-post interventions; 3 RCTs; 3 quantitative descriptive studies); another four were qualitative evaluations, and two used mixed methods. The lack of correspondence between study designs, and characteristics of the training programs (e.g. aims, approaches, populations of interest, outcomes) does not allow for numerical pooling of the outcome data [9]. Thus, a narrative synthesis was conducted.

\section{Training for healthcare and education professionals}

Overall, the nine evaluations of ED training for healthcare and education professionals focused on knowledge translation and skill building, prevention, and professional development. Training programs were geared toward specific groups: health care professionals including dentists [10, 11], nurses [12], social workers [13], multidisciplinary health professionals $[14,15]$, and educators
[16-18] . Five evaluations found that training significantly improved trainees' knowledge, skills, and confidence to assess, treat, or teach on eating disorders $[10,11,15,17,18$,]. McVey et al. [18] reported better linkages among ED practitioners, while Rosenvinge et al. [15] documented strong interest in working inter-professionally, or in starting new services, as a result of training.

\section{Training for families and significant others}

Findings from the ten evaluations of ED training for families and other carers also revealed that training improves knowledge and related skills. Yet, most important or this group are findings related to reduced distress and burden, better coping and communication [19-22] and improved family functioning [19, 23]. Trainees needed to be affirmed as good parents, and found that the skills acquired in ED training were transferrable to other areas of parenting [5, 24]. The need for connectedness and support, particularly among parent trainees, emerges as a key theme: being able to break isolation and "externalize the illness" [19]; the need for ongoing exchange with others [19, 25], and extended support through "alumni groups" or "buddy" systems [26].

\section{Training for the public}

Hart et al. [27] evaluated a training program that adapted the Mental Health First Aid (MHFA) protocol for serious mental illnesses to ED. They demonstrated that ED knowledge and helping strategies may be effectively disseminated to the general public. The MHFA training was associated with more accurate recognition of eating disorders, greater knowledge of effective treatments and helping strategies, and confidence in providing help.

\section{Discussion and conclusions}

This review underlines the international scope of interest in ED training, and a more frequent focus on training for people with an ED diagnosis than on prevention. While all the evaluations assessed outcomes for trainees, very few included questions on training effectiveness from the patient perspective; and none controlled for possible confounding influences on training outcomes. Future research is needed to determine the intensity of training required to sustain improvements in ED knowledge and skills. As well, follow-up studies should establish a stronger link between improved knowledge and better care for sufferers. It would also be important to develop training fidelity measures.

The results suggest that the orientation of ED training varies with the interests and needs of different trainee groups. Whereas healthcare professionals and educators are concerned with the overall development of the ED field, and dissemination of best practices, training for 
the public at-large promotes familiarity with ED and actual contact between ordinary citizens and ED patients, addressing the critical issues of social distance and stigma in mental health populations [28, 29]. Moreover, family involvement with ED is particularly intense and personal, identifying them as not only trainees, but a potentially vulnerable target group. Results suggest that the supportive, face-to-face element of training for families and natural supporters, both between trainers and trainees and among trainees themselves, was highly beneficial. This implies that ED training using passive learning approaches may be less effective for families, for whom the lived experience of training was an added value.

The heterogeneity of these studies, divergent objectives of the training programs, and the wide array of methodologies employed precluded a more in-depth comparison of individual studies, or subgroups. Nonetheless, the review does provide a comprehensive overview of research on ED training initiatives that should be of interest to healthcare practitioners, educators, and families involved with the management or prevention of $\mathrm{ED}$, as well as the interested public.

\section{Endnote}

${ }^{1}$ The number of studies reported here totals 22 , instead of 20. This occurred because two studies, McVey, 2005, and 2007 cut across two professional groups (healthcare professions and educators), and both age groups (children, and all ages), so are counted twice.

\section{Competing interests}

The authors declare that they have no competing financial, professional or other interests that may have influenced the research described in this manuscript.

\section{Authors' contributions}

The literature search, data extraction and charting were conducted by (blinded for review) (MP) and (blinded for review) (AP). (Blinded for review) (JS) worked on data synthesis under supervision of (Blinded for review) (MP). (HS) and (MI) were the Expert Panel. They reviewed the list of studies extracted for the review and suggested other authors that might have published evaluative studies on eating disorder training programs. All authors read, provided comments, and approved the final manuscript.

\section{Acknowledgements}

Funding for this research was provided by the Canadian Institutes of Health Research Grant \# 261757.

\section{Author details}

'Douglas Mental Health University Institute, McGill University, 6875 LaSalle Boulevard, Verdun, Montreal, Québec H4H 1R3, Canada. ${ }^{2}$ Douglas Mental Health University Institute, Montreal, Canada. ${ }^{3}$ École de Réadaptation, Université de Montréal, Montréal, Canada.

Received: 7 May 2015 Accepted: 31 July 2015

Published online: 14 August 2015

\section{References}

1. Davis K, Drey N, Gould D. What are scoping studies? A review of the nursing literature. Int J Nurs Stud. 2009;46(10):1386-400. doi:10.1016/ j.jnurstu.2009.02.010
2. Arksey H, O'Malley L. Scoping studies: Towards a methodological framework. International Journal of Social Research Methodology. Theory Pract. 2005;8(1):19-32. doi:10.1080/1364557032000119616.

3. Goddard E, Macdonald P, Treasure J. An examination of the impact of the maudsley collaborative care skills training workshops on patients with anorexia nervosa: A qualitative study. Eur Eat Disord Rev. 2011;19(2):150-61.

4. Gurney WW, Halmi KA. Developing an eating disorder curriculum for primary care providers. Eat Disord. 2001;9(2):97-107.

5. Leichner P, Hall D, Calderon R. Meal support training for friends and families of patients with eating disorders. Eat Disord. 2005;13(4):407-11.

6. Treasure J, Sepulveda AR, Whitaker W, Todd G, Lopez C, Whitney J. Collaborative care between professionals and non-professionals in the management of eating disorders: A description of workshops focussed on interpersonal maintaining factors. Eur Eat Disord Rev. 2007;15(1):24-34.

7. Treasure J, Whitaker W, Todd G, Whitney J. A description of multiple family workshops for carers of people with anorexia nervosa. Eur Eat Disord Rev. 2012;20(1):e17-22.

8. Munn Z, Tufanaru C, Aromataris E. Data extraction and synthesis. Am J Nurs. 2014;114(7):49-54. doi:10.1097/01.NAJ.0000451683.66447.89.

9. Robertson-Malt S. JBIs systematic reviews: Presenting and interpreting findings. Am J Nurs. 2014;114(8):49-54. doi:10.1097/ 01.NAJ.0000453044.01124.59.

10. Debate RD, Cragun D, Gallentine AA, Severson HH, Shaw T, Cantwell C, et al. Evaluate, assess, treat: Development and evaluation of the EAT framework to increase effective communication regarding sensitive oralsystemic health issues. Eur J Dent Educ. 2012;16(4):232-8.

11. DeBate RD, Severson H, Zwald ML, Shaw T, Christiansen S, Koerber A, et al. Development and evaluation of a web-based training program for ora health care providers on secondary prevention of eating disorders. J Dent Educ. 2009;73(6):718-29.

12. Abuel-Ealeh M, Ashbey R, Barrett R. Survey of students from an eating disorders programme. NURS STAND. 2001;15(47):33-9.

13. Gurney WW, Halmi KA. An eating disorder curriculum for primary care providers. Int J Eat Disord. 2001;30(2):209-12

14. Pettersen G, Rosenvinge JH, Thune-Larsen KB, Wynn R. Clinical confidence following an interprofessional educational program on eating disorders for health care professionals: A qualitative analysis. J Multidiscip Healthc. 2012;5:201-5.

15. Rosenvinge JH, Skårderud F, Thune-Larsen KB. Can educational programmes raise clinical competence in treating eating disorders? Results from a Norwegian trial. Eur Eat Disord Rev. 2003;11(4):329-43.

16. Chally PS. An eating disorders prevention program. J Child Adolesc Psychiatr Nurs. 1998;11(2):51-60

17. McVey G, Tweed S, Blackmore E. Healthy Schools-Healthy Kids: A controlled evaluation of a comprehensive universal eating disorder prevention program. Body Image. 2007:4(2):115-36.

18. McVey GL, Davis R, Kaplan AS, Katzman DK, Pinhas L, Geist R, et al. A community-based training program for eating disorders and its contribution to a provincial network of specialized services. Int J Eat Disord. 2005;37(SUPPL):S35-40.

19. Goodier GHG, McCormack J, Egan SJ, Watson HJ, Hoiles KJ, Todd G, et al. Parent skills training treatment for parents of children and adolescents with eating disorders: A qualitative study. Int J Eat Disord. 2014;47(4):368-75.

20. Grover M, Naumann U, Mohammad-Dar L, Glennon D, Ringwood S, Eisler I, et al. A randomized controlled trial of an Internet-based cognitivebehavioural skills package for carers of people with anorexia nervosa. Psychol Med. 2011:41(12):2581-91.

21. Haltom C, Ribeiro R, Potter N. Collaborative professional education for carers of those with eating disorders. Eur Eat Disord Rev. 2012;20(4):311-4.

22. Pépin G, King R. Collaborative Care Skills Training workshops: Helping carers cope with eating disorders from the UK to Australia. Soc Psychiatry Psychiatr Epidemiol. 2013;48(5):805-12.

23. Sepulveda AR, Lopez C, Macdonald P, Treasure J. Feasibility and acceptability of DVD and telephone coaching-based skills training for carers of people with an eating disorder. Int J Eat Disord. 2008;41(4):318-25.

24. Zucker NL, Marcus M, Bulik C. A group parent-training program: A novel approach for eating disorder management. Eat Weight Disord. 2006;1 (2):78-82.

25. Sepulveda AR, Lopez C, Todd G, Whitaker W, Treasure J. An examination of the impact of "the Maudsley eating disorder collaborative care skills workshops" on the well being of carers. Soc Psychiatry Psychiatr Epidemiol. 2008;43(7):584-91. 
26. Zucker NL, Ferriter C, Best S, Brantley A. Group parent training: A novel approach for the treatment of eating disorders. Eat Disord. 2005;13(4):391-405. doi:10.1080/10640260591005272.

27. Hart LM, Jorm AF, Paxton SJ. Mental health first aid for eating disorders: Pilot evaluation of a training program for the public. BMC Psychiatry. 2012;12:98.

28. Alexander LA, Link BG. The impact of contact on stigmatizing attitudes toward people with mental illness. J Ment Health. 2003;12(3):271-89.

29. Corrigan P, Markowitz FE, Watson A, Rowan D, Kubiak MA. An attribution model of public discrimination towards persons with mental illness. J Health Soc Behav. 2003;44(2):162-79.

Submit your next manuscript to BioMed Central and take full advantage of:

- Convenient online submission

- Thorough peer review

- No space constraints or color figure charges

- Immediate publication on acceptance

- Inclusion in PubMed, CAS, Scopus and Google Scholar

- Research which is freely available for redistribution 